\title{
Challenges in Managing Disability in Higher Education, Illustrated by Support Strategies for Deaf and Hard of Hearing Students
}

\author{
Matthew Brett
}

Disability and Equity Programs, Academic Enrichment Services, University of Melbourne, Victoria 3010, Australia

\begin{abstract}
There has been a significant and consistent increase in the numbers and proportion of students disclosing disability at enrollment in Australian higher education. The growth in student numbers has paralleled the introduction and enhancement of legislative and policy instruments that enable their participation. Whilst significant changes are evident in higher education institutional and policy contexts which demonstrate a willingness and commitment to enabling student participation, significant challenges remain in implementing services that support the participation, learning and success of students experiencing disability. The intersection between disability and higher education results in complex problems for which innovative solutions are required. This complexity is evident in the participation of those with profound hearing impairments. Service delivery methods that function effectively in community or other educational contexts are not adequate in higher education contexts. The sophisticated language and conceptual requirements of higher education are not well accommodated through the dominant support models of Auslan (Australian sign language) interpreting and notetaking. In this context, a support model involving the provision of live captions has been successfully trialled at an Australian university. This is now the dominant mode of support for the university's students with profound hearing impairments. The implementation of live captioning, and its adoption at other institutions within Australia, provides insights into practices that are effective in enabling student participation in higher education.
\end{abstract}

Keywords: Deaf students, Australian higher education, disability support, live remote captioning.

\section{DISABILITY AND HIGHER EDUCATION IN AUSTRALIA}

Students with disabilities were identified as an equity group at the inception of Australian higher education equity policy, articulated in 1992 in A Fair Chance For All [1]. Data on the participation of students with disabilities around this time was limited, with systematic data collection occurring after the development and publication of Equity and General Performance Indicators in Higher Education [2]. Since 1996, Australian universities were required to ask all students at enrollment, "Do you have a disability, impairment or long term medical condition which may affect your studies?" [3]. Students are also requested to indicate whether their disability belongs to the categories of hearing, learning, medical, mobility, visibility or other [3]. Reponses to the enrollment declaration enable routine reporting of access rates, participation rates, participation ratios, success ratios and retention ratios [3]. The participation rate and absolute number of students with disabilities has increased every year since data collection commenced [3-5]. In 1998 there were 17,574 domestic students enrolled in a higher education program who had disclosed disability at enrollment, and in 2008 this figure had risen to 30,872 . Students disclosing disability now comprise $4.07 \%$ of all domestic students [6].

The growth of students disclosing disability at enrollment is one way of understanding disability within an education

*Address correspondence to this author at the Disability and Equity Programs, Academic Enrichment Services, University of Melbourne, Victoria 3010, Australia; Tel: 6138344 4244; Fax: 6138344 5323;

E-mail: mcbrett@unimelb.edu.au context, but it does not comprehensively represent disability within higher education. Many students disclose a disability and have no underlying impairment [3]. Some students identify with the concept of disability but do not disclose at enrollment for reasons that include fear of stigma [7], while other students acquire an impairment or disability after they have completed their enrollment declaration [7]. Many students have an underlying impairment, which may be considered a disability, but do not identify with the concept of disability and do not disclose at enrollment [7]. Students who identify disability at enrollment are not always clients of university disability services [7]. A challenge in any work focusing on disability is addressing the conceptual ambiguity associated with the term disability. It is acknowledged that reports and statistics cited within this paper are imperfect representations of disability, but this does not undermine the central themes of the paper. More students are disclosing disability, while the policy context is becoming more complex, and this poses significant challenges for service providers.

\section{THE POLICY CONTEXT}

The participation of students disclosing disability (subsequently referred to as students) has been facilitated by a range of institutional and policy instruments. Each new development and iterative refinement of these policy instruments has served to enable further student participation, making the intersection of higher education and disability more complex. To demonstrate, changes to the Disability Discrimination Act undertaken in 2005 [8] extended the requirements of education providers from a requirement not to discriminate (through actions that include denial of, or limiting access to benefits provided by the 
provider) to a requirement which makes unlawful the development or approval of curriculum that excludes people with disability from participation. More recent changes to the Disability Discrimination Act in 2009 embed concepts of reasonable adjustments within the primary rather than subordinate legislation of the Disability Standards for Education [9].

In addition to anti-discrimination legislation, mechanisms have been established to facilitate student participation in higher education. The Australian Federal Government Department of Education, Employment and Workplace Relations established the Disability Support Program to offset the costs incurred by universities in providing support for students with disabilities. Provision for $\$ 6,479,000$ in expenditure under the Disability Support Program was made in 2005 [10]. Through the Disability Support Program, universities are partially reimbursed for disability services expenditure.

As more students participate in higher education, the legislative context has been amended in ways that endeavor to enable student participation, and complementary policies support this objective with direct institutional funding support. There remains however, ambiguity about what it means in practical terms to enable students' participation in higher education institutions. It is useful in this context to examine specific examples of student participation. To this end, the experiences of students with hearing impairments are useful for understanding the challenges associated with enabling participation, and how institutions innovatively respond to this challenge. Prior to examining specific issues for students with hearing loss, consideration must first be given to hearing loss and Deafness and disability in Australia.

\section{DEAFNESS, HEARING IMPAIRMENT AND DISABILITY}

The incidence of hearing impairment in Australia is significant, with nearly 1.4 million Australians estimated to have a disabling level of hearing disorder in 2003 [11]. This is comparable to 1998 estimates that $6.9 \%$ of the Australian population had a disease of the ear [11]. It is inappropriate, however, to assume that this figure is representative of participation rates in higher education for students disclosing disability, and in particular, hearing related disability. Factors that reduce the number and proportion of students who would experience hearing related disability include the heightened incidence of disability with age [11], the more frequent incidence of mild forms of hearing loss with which there is reduced likelihood that individuals will identify as having a disability, and the incidence of hearing loss in one rather than both ears.

Within the spectrum of hearing loss, a distinction is made between those who are life-long users of sign language, and those with hearing loss who communicate through the English language [12]. The Deaf community often sees itself as a distinct cultural linguistic minority rather than a disability group. The use of the capitalised "Deaf" relates to people who identify as belonging to the Australian Deaf community. The size of the Australian Deaf community is estimated at 6,500, with a decrease in size projected over the coming years as new additions to the Deaf community decrease. This contraction is attributed to immunisation and genetic screening programs, increased incidence of cochlear implants in children and oral education strategies [12]. Whilst Australian Sign Language (Auslan) is recognised as a community language by government [13], the decreasing size of the Deaf community leads to problems in maintaining a minimal linguistic community, or having enough users of the language to uphold a sustainable level of meaningful communication between users [12].

Not all people with severe or profound levels of hearing loss are members of the Deaf community. In the Australian population, an indicator of population size of those with hearing impairment related functional impact is the number of TTY users. A TTY is a teletypewriter that enables those who are unable to use standard telephony services to communicate via typed text messages. There are estimated to be 12,800 TTY users in Australia, with $41 \%$ of this group using Auslan, and 52\% using English speech [14].

\section{HEARING IMPAIRMENT IN HIGHER EDUCATION}

In a higher education context, mild forms of hearing loss are less likely to have a functional impact on academic participation. Severe and profound levels of hearing impairment are more likely to result in functional difficulty with accessing spoken language, which in most academic contexts is the primary mode of instruction and knowledge transmission in the classroom. These students are more likely to be excluded from participation, more likely to require services to enable their participation, and more likely to self identify in questions relating to disability status.

Whilst over 30,000 university students in Australia disclosed disability at enrollment in 2008, the number of students disclosing hearing related disability is a subset of this group. Data on the types of disability disclosed are not routinely reported, but data from 1996 to 2002 [3] demonstrates that hearing impairment comprises approximately $10 \%$ of disability disclosures.

At a local level, disclosure trends at a national level were similar to that of the University described in this paper with a stable $10 \%$ of disability disclosures being for the hearing category in a context of rising total disability disclosures. Most students who disclose at enrollment do not use disability services, with only 40 of the 122 students who disclosed a hearing related disability at the University in 2008 having contact with the institution's disability service. Of these 40, only 2 would be considered members of the Australian Deaf community.

\section{SUPPORTING STUDENTS WHO ARE DEAF OR HARD OF HEARING}

Having clarified the numbers of students disclosing hearing impairment at the University, and clarified key concepts relating to hearing impairment and the Deaf community, it is useful to consider the types of support mechanisms provided to Deaf and hard of hearing students and the ways in which tertiary institutions have enabled student participation.

Students who are Deaf or hard of hearing are generally supported in ways that are consistent with functional impairment and level of participation restriction. For those with mild to moderate forms of hearing loss, participation 
has traditionally been facilitated through enabling preferential seating or hearing augmentation devices (such as audio loops in learning environments) [15]. For students with more significant levels of hearing loss, notetakers may be considered [15]. For students who identify as being Deaf, Auslan (Australian Sign Language) interpreters are considered [15].

The provision of hearing augmentation devices is considered within Australian Standards [16]. Audio loop installation is cited as an enhanced, rather than minimum accessibility standard [17]. The University explored in this paper has adopted the enhanced standard, making audio loops a pervasive feature of its learning environments.

For students whose comprehension of spoken information in academic environments is sub-optimal, with or without hearing augmentation devices, notetakers have been identified as an appropriate form of support [18, 15]. Notetakers are employed to document the key concepts communicated in a lecture in conventional note form, not provide a verbatim transcript of instruction [19]. Whilst notetakers enable students with a reasonable level of speech comprehension to focus exclusively on an instructor's speech without the distraction of taking notes simultaneously, it is less effective for students whose speech comprehension is low. Gaps arise between what information the speaker conveys, what is perceived, and what is documented in the form of notes. There has, however, been little by way of alternatives in support provision for this student group, and notetaking has been the most frequent form of support for students with significant hearing loss who are not members of the Deaf community. It is unclear why the problems associated with this support model have not been addressed through alternative support models.

For students who are members of the Deaf community, interpreters are generally provided, irrespective of the level of hearing loss that is associated with their use of Auslan [14]. In a higher education context, interpreting work is demanding because information transmission is dense and utilises complex language. Two interpreters are required for each lecture or tutorial, taking turns in $15-20$ minute intervals [20]. Notetakers are also employed such that students can focus on the speaker, the interpreter, and other visual cues without the distraction of taking notes simultaneously. These support arrangements mean that Deaf students are the most expensive group of students with disability to support [21].

The Deaf student support model, whilst the dominant form of support in Australia for many years, is problematic in many respects. There are long-standing interpreter shortages in Australia. A 2003 study found that an interpreter was available for only $39 \%$ of occasions in key service areas (legal, employment, medical, and educational settings) where an interpreter was required. The figure was higher for education at $80 \%$, but still translates to students, on average, having little or no access to the language of instruction in 1 out of 5 classes [19]. Gaps inevitably arise in student learning.

In addition to interpreter shortages, there are inherent difficulties associated with interpreting in a higher education context. Fewer Deaf people have made the journey through higher education, with $14 \%$ of Deaf people having completed a higher education qualification, as opposed to $27 \%$ of the general population [19]. Comparatively lower involvement with higher education has decreased the exposure of Auslan to specific academic vocabulary. In higher education contexts, Auslan interpreters will manually fingerspell rather than have a sign for many discipline specific words and concepts. The lexicalisation of finger spelling into Auslan [22] is less likely in a context where there is limited discussion of discipline specific vocabulary in the broader Deaf community. Interpreters are expected therefore to move between spoken English and Auslan using a high rate of manual letter by letter finger spelling. The clarity and validity of knowledge and information transmission is diminished as a result.

An association with the membership of a cultural linguistic minority group leads to a strong expectation that Auslan interpreting will be provided in education environments. Of complaints heard in the Australian Federal Court under disability discrimination legislation in the realm of education, 4 out of 15 hearings related to the provision of Auslan interpreters [23]. No cases have been heard that related to access to services for students who are hard of hearing. Work has been undertaken to find ways of enhancing access to interpreters and growing the pool of interpreters [24]. Options highlighted, such as video relay interpreting, are problematic due to bandwidth requirements. Australia's telecommunications and broadband internet infrastructure are the topic of significant debate, with the current infrastructure limiting the use of Auslan across video conferencing facilities to a small range of locations with high bandwidth facilities. There has been limited consideration of alternatives to interpreting or notetaking that may complement existing support models. Text based support systems have been identified as a low priority as Deaf students often have difficulty with English literacy, with conclusions drawn that information should be represented in a visual (non textual) form [24]. This conclusion supports the cultural linguistic minority perspective, with strong preferences for contemporaneous Auslan interpreting support models.

A significant challenge is evident at an institutional level for enabling support for Deaf students. This group has a legitimate expectation that services will be provided, but interpreting availability is limited. Predictions of a contraction in the size of the Deaf community [11] may alter the interpreter supply and demand equation in the short term, but alternative support mechanisms will need to be considered if Auslan is to have a decreasing role in the communication of students with hearing related disability.

\section{ALTERNATIVES}

Universities have a mechanism for accessing funds that cover the costs of service provision, and are required to provide services by law to enable student participation, but are unable to do so due to capacity constraints. This scenario is changing through innovative practices within Australian higher education.

An Australian university commenced consultation focus groups with students on their experiences of disability services every semester from 2003 to 2006. Feedback 
provided from students consistently highlighted the issue of access to interpreting. Steps were taken to improve the proportion of classes that could be covered with interpreters, but these efforts proved to be futile. In parallel, several students with hearing impairments on exchange and study abroad programs with the university made enquiries about the provision of real time captioning services, a service model which involved speech to electronic text, rather than speech to Auslan or speech to handwritten notes. Enquiries with Australian captioning providers indicated that access to staff with the capacity to provide real time captioning services (stenocaptioners) was limited, with most stenocaptioners based along side Australia's broadcasting hub in Sydney, New South Wales, rather than Victoria where the university was located. There was, however, the capacity to maximise access to stenocaptioners in a cost effective manner, and in a low bandwidth environment through a remote service delivery model.

In 2006, a pilot was undertaken to trial the provision of Live Remote Captions. A call for expression of interest was distributed to students who were Deaf or hard of hearing. Four students expressed an interest, two were members of the Deaf community, and two were not. All were surveyed pre-pilot about their preferred modes of communication and strategies for accessing information across personal, entertainment, social and academic domains. All students indicated a reliance on text based communication and information sources including the internet, instant messaging, SMS, subtitled videos and closed captions. This finding challenged an assumption within Deaf student support that support provision should avoid the use of English text. By the time of the pilot, one student was on leave of absence, two had withdrawn interest, leaving one interested student.

A key challenge in establishing Live Remote Captions was providing the stenocaptioner with a high quality audio feed. This was established through providing the lecturer with a high quality microphone and transmitter, the signal from which was processed by an electronic device connected to a telephone and transmitted to the remotely based stenocaptioner, located 1,000 kilometers away.

Stenocaptioners use a phonemic system to represent phonemes through a specialised key pad called a Stentura. Through pressing various combinations of keys, phonemes heard during speech can be represented. Those phonemes are then processed by a computer dictionary which can match the phonemes with English words. The resulting English text is produced at an accuracy rate of $98 \%$, and distributed to the internet, where it is accessed by the student in class with a delay of less than 2 seconds. The development of Live Remote Captioning was an innovation for the Australian context. The provision of Live Captions and Live Remote Captions has occurred previously in other countries where local characteristics had facilitated its introduction. Speech to text support models has been available in the United States of America since 1982 [25].

Whilst the initial pilot involved a single student for 1.5 hours per week, the proof of concept, quality of student feedback, and transferability of the service led to a rapid uptake of the service to other students within the university and in other Australian tertiary education environments. Live
Remote Captioning is now used almost exclusively at the university, forming $95 \%$ of demand for services from students with profound hearing impairment. The remaining $5 \%$ is met through traditional Auslan interpreting services. Close to $100 \%$ of demand for services is met, as opposed to $72 \%$ when Auslan was the primary mode of service delivery. Students of the University who are Deaf or hard of hearing have not raised issues in consultation focus groups about access to services in lectures since the introduction of Live Captioning Services. At least 10 other universities in Australia now use Live Remove Captioning to support Deaf and hard of hearing students where similar issues are experienced in accessing interpreters for deaf student support.

\section{LESSONS FOR MANAGING DISABILITY IN HIGHER EDUCATION}

There is a heightened expectation that Australian higher education institutions will be more accessible to students experiencing disability. This expectation is being realized through increased numbers of students disclosing disability and seeking disability related services. The provision of these services is not a straightforward proposition. In exploring support considerations for Deaf and hard of hearing students, who form around $10 \%$ of disability disclosures, it is evident that existing support models have been ineffective at facilitating learning for many students.

The enrollment declaration category of 'hearing' includes a range of students with varying degrees of support requirements. The needs of many students with hearing impairment are addressed through features of the built environment, with the installation of hearing augmentation devices reducing the need for additional services. Students who are members of the Deaf community have relied primarily on an Auslan support model, where text based alternative support strategies have not routinely been implemented due to an assumption that Deaf students may have difficulty in using English. The Auslan support model has problems associated with interpreter availability and the challenge of moving from English to Auslan within a discipline specific language context. Students who have a significant level of functional hearing impairment, but are not members of the Deaf community, have relied primarily on a notetaking support model. Alternative support models have not routinely been implemented for this group. The notetaking support model can lead to gaps between the information and knowledge transmitted, documented, and received.

In the case of the university described in this paper, the need for an alternative support model was identified through the establishment of a consultation focus group. It is unclear why, when information about the problems associated with various support models for Deaf and hard of hearing students have been known in the Australian context for some time, alternative support systems such as Live Remote Captioning have not been introduced sooner. An answer to this question is difficult to discern with any degree of certainty, but contributing factors can be alluded to in the information that has been included within this paper by the author, who was responsible for establishing the consultation focus groups, for analysing the responses, and implementing the novel (in 
an Australian context) Live Remote Captioning support model.

The maturation of the Australian legislative and policy context on the participation of students with disability in higher education poses significant challenges for disability service provision. In the case of Deaf and hard of hearing students, disability services are involved in a range of interventions across the University. The physical infrastructure of learning environments may need to be modified to accommodate hearing augmentation devices, requiring interactions with staff responsible for the physical environment. Relationships with notetakers, interpreters and caption providers need to be developed and maintained. Academic staff may need to be contacted to discuss the implications of having classes interpreted or captioned, and they may be called upon to provide access to discipline specific vocabulary. A complex range of interventions and relationships required for enabling student participation is evident across disability categories. In a resource constrained environment, choices often need to be made about which interventions and relationships should be given greater relative priority.

Whilst disability disclosure rates have been increasing in Australia, it is important to recognize within a service delivery environment that disclosure is only part of the complex interaction between students and environment. Disclosure can take many forms including, enrollment declarations, requesting supports within a designated disability service, participating in consultation focus groups, or making complaints through disability discrimination legislation. Staff involved in delivering a higher education disability service should be mindful of the various ways in which students disclose when making choices about which issues should be targeted for greater relative priority in intervention and relationships. In this university's case the choice to respond to feedback on the lack of interpreter access has led to new Deaf and hard of hearing student support models that have been rapidly taken up within the university and broader higher education environment.

\section{REFERENCES}

[1] Department of Employment Education Training; National Board of Employment, Education and Training. A fair chance for all: National and institutional planning for equity in higher education. A discussion paper. Canberra: Australian Government Publishing Service, 1990.

[2] Martin LM. Equity and general performance indicators in higher education. Equity indicators. Canberra: Australian Government Publishing Service,1994; vol. 1.

[3] James R, Baldwin G, Coates H, Krause KL, McInnis C. Analysis of equity groups in higher education 1991-2002. Melbourne: The University of Melbourne Centre for the Study of Higher Education 2004.

[4] Department of Education Employment and Workplace Relations. Review of Australian Higher Education. Final report. Canberra: Australian Government Publishing Service 2008.

[5] Department of Education, Employment and Workplace Relations. Students 2008 [full year]: Selected higher education statistics. Canberra: Australian Government Publishing Service 2009.
[6] Department of Education, Employment and Workplace Relations. Institutional student equity performance data 2007. Canberra: Australian Government Publishing Service 2009.

[7] Brett M, Kavangah L. Are a few veggie burgers enough? 10th Pacific Rim First Year in Higher Education Conference 2007: Conference Proceedings. Brisbane, Australia: Queensland University of Technology 2007.

[8] Disability Discrimination Act, Act No. 86. Canberra: Attorney General's Department 2005.

[9] Disability Discrimination Act, Act No. 70. Canberra: Attorney General's Department 2009.

[10] Higher Education Support Act 2003: Other grants guidelines. Canberra: Attorney General's Department 2006.

[11] Australian Institute of Health and Welfare. Disability in Australia: Trends in prevalence, education, employment and community living. Canberra: Australian Government Publishing Service 2008.

[12] Johnston T. W(h)ither the Deaf Community? Population, genetics and the future of Auslan (Australian Sign Language). Am Ann Deaf 2004; 148(5): 358-75.

[13] Department of Employment Education and Training. The Australian Language and Literacy Policy. Policy Information paper ('White' paper); Companion volume to the policy paper. Canberra: Australian Government Publishing Service 1991.

[14] Department of Communications, Information Technology and the Arts. Teletypewriter (TTY) use in Australia. Canberra: Australian Government Publishing Service 2005.

[15] McLean P, Osborne V, McAuliffe J, Housden T, Revens E. Optimising the learning experience for Deaf and hearing impaired students. Victoria, Australia: Victorian Co-operative Projects Higher Education Students with a Disability Committee 1999.

[16] Australian Standards. A S 1428.2. Australian standard design for access and mobility. Part 2: Enhanced and additional requirements- Buildings and facilities. Sydney: Standards Australia International Limited 1992.

[17] Australian Standards. A S 1428.1. Design for access and mobility General requirements for access - New building work. Sydney: Standards Australia International Limited 2001.

[18] O'Connor B, Watson R, Power D, Hartley J. Students with disabilities: Code of Practice for Australian Tertiary Institutions. Commonwealth of Australia Department of Education Training and Youth Affairs. Brisbane: QUT Publications and Printing 1998.

[19] Al Mahmood R, McLean P, Powell J, Ryan J. Towards success in tertiary study: With deafness. Victoria, Australia: Victorian Cooperative Projects Higher Education Students with a Disability Committee 1998.

[20] ORIMA Research. Supply and demand for Auslan interpreters across Australia. Canberra: Department of Family and Community Services 2004.

[21] Andrews RJ, Smith J. Additional costs of education and training for people with disabilities: Final report to the Department of Employment, Education and Training. Canberra: Australian Government Publishing Service 1992.

[22] Johnston T, Schembri A. Australian Sign Language (Auslan): An introduction to sign language linguistics. Cambridge: Cambridge University Press 2007.

[23] Australian Human Rights Commission. Court Decisions. Available from: http://www.hreoc.gov.au/disabilityVirights/decisions/court/court. html [Cited: 2009 Nov 25].

[24] Knuckey J, Lawford L, Kay J. Information should be visual: New and emerging technologies and their application in the Vet Sector for students who are Deaf and hard of hearing. Leabrook, South Australia: National Centre for Vocational Education Research, Australian National Training Authority 2001

[25] Stinson M, Eisenberg S, Horn C, Larson J, Levitt H, Stuckless R. Realtime speech-to-text services. A report of the National Task Force on Quality of Services in the Postsecondary Education of Deaf and Hard of Hearing Students. Rochester, NY: Northeast Technical Assistance Centre, Rochester Institute of Technology 1999. 